\title{
CHALLENGES AND WEAKNESSES OF AGILE METHOD IN ENTERPRISE ARCHITECTURE
}

\author{
Zahra Askarinejad Amiri ${ }^{1}$ \\ ${ }^{1}$ Department of Computer Engineering, Staffordshire University \\ zahra.askarinejad@gmail.com
}

\begin{abstract}
As Information Technologies (IT) grow in complexity and scope, the need for a coherent approach to enterprise wide modelling becomes paramount. Changing is one of the most important challenges that organisation encounter. The topic of enterprise architecture has been gaining significant attention from both academia and industry due to the inefficiencies of current IT architecture to cope with rapid changes in business environment. Apart from that, Agile is new concept that present in EA recently. It tries to be adaptive with frequently changes which occurred in organisation. There are some agile methodology and method with maintain agile manifesto. Briefly they use agile practices in their development such as XP, Scrum and service oriented architecture. Each of them follows some challenges that lead to less usability of them in EA. This research intends to identify these challenges and proposed method to improve the usability of agility in enterprise architecture.
\end{abstract}

\section{KEYWORDS}

Enterprise architecture, agility, agile method, agile EA.

\section{INTRODUCTION}

Today's, using Information Technology (IT) become more popular in many organization particularly large enterprise. So, it led to provided new notion as Enterprise Architecture (EA). Interestingly enough, EA is blend of enterprise and architecture. IEEE Standard 1471-2000 defines architecture in enterprise as "The fundamental organization of a system, embodied in its components, their relationships to each other and the environment, and the principles governing its design and evolution." It acts like a bridge which connects business and IT.

There are several definitions about enterprise architecture, but totally we can say that an Enterprise Architecture (EA) identifies the main components of the organization, it is information systems, the ways in which these components work together in order to achieve defined business objectives, and the way in which the information systems support the business processes of the organization.[1]

The topic of enterprise architecture has been gaining significant attention from both academia and industry due to the inefficiencies of current IT architecture to cope with rapid changes in business environment. [2] Therefore each organization must accomplish EA accurately to identify their requirement and recognise the problems of the system to solve them. It is sensible way to use EA in enterprise to handles software development. Manager must consider the usability and effects of EA. Nevertheless, there are some problems in EA such as costly and slowly trend which sometimes led to fail the EA in system.

DOI : $10.5121 /$ ijcses.2012.3603 
Industrialization and modernization provide competitive marketing. Frequently changing lead to organisation tends to use agile method. In fact, agility in business is effective element for financial benefit of enterprise. Enterprise architecture provides bridge between IT and business to assist the firms. In addition Agile add to EA to concentrates on project delivery. So the aim of agile EA is worked parallel with business. Each agile methodology uses some agile practices. Agile practices follow the agile manifesto. Therefore, for applying agility in each enterprise must apply some agile practices. This research first is indicated the available method for agile enterprise architecture and then is determined the challenges of each of them. Based on existing literature and survey some agile practices are more efficient and are used more in enterprise. And then researcher will discusses about less usability of agility in EA and what is the existence issue in this area and how can be solve it.

\section{AGILE ENTERPRISE ARCHITECTURE METHOD}

In practice, software engineering is continuous improvement. Traditionally, the software product produces due to individual ability. By growing the technology the number of complex software rise, consequently the software faced with divers demands and requirements which are more difficult to understand and implement them. Likewise, constantly changing in demand and customer requirement acquire to scientists attract to agile concept. Controlling the project based on traditional cycle is difficult and even some time is impossible. Nowadays user demands changing rapidly and therefore industry must be adaptable with these.

All above reasons cause to developers trend to agile concept in software development. Agile practices emphasise on people, incremental and iterative approach. In addition, agile method handling the changes of the requirement during lifecycle development, spreading the collaboration of stakeholder, customer, project team member and software developer and also it provides the constant and early delivery of the product. [3]In agile method the software project divided in smaller version and has frequently communication with customer to get their feedback. It is just rely to necessity document. It means that documentation is little and it does not spend a lot of time. So rising of agility in enterprise architecture lead to many previous challenges of the company solve and also some challenges appeared. Anyway, with regard to advantages and usability of them, they are handled some challenges that will be discussed briefly based on available context.

\section{CHALLENGES OF AGILE ENTERPRISE ARCHITECTURE}

Although the necessity of agile approach in industry is inevitable but some challenges of them lead to many manager don not use it. Some agile method will be defined and evaluated specifically to declare the challenges of Agility based on them.

\subsection{Scrum}

One of efficient and popular management agile method in industry is Scrum. "Scrum has been used with the objective of simplifying project control through simple processes, easy to update documentation and higher team iteration over exhaustive documentation".[4] In scrum, project split in to succinct activity that called sprint. Each sprint lasts about one or two weeks. After finishing each sprint the team developer assesses the step and decides about the planning and details of the next sprint. This is efficient feature of this method that let to stockholders and 
member determine how to continue the project based on available information that achieve in previous sprint. And also, this way is reliable more than prediction at the beginning of the project.

The Scrum method, consist of rules, roles and production are fixed in scrum strategy and enterprise is changed based on it. Actually, scrum is method of agile software which is welcome to changing and delivery the product early. Development teams try to import Scrum software as an agile method to improve the productivity and software development and quality by using scrum principle and its methods. According to Guang-yong, "Among 1000 professional developers $20.9 \%$ using the Scrum model which ranked in the forefront of agile development methods and models".[5] It managing the project radically and also provide decision making authority in operation level.[6]

Nevertheless, Scrum handles some challenges in organization that must be considered and also some of them are:

- It is appropriate for small project and also small team. It cannot handle large enterprise Based on this methodology. [7] In fact, in enterprise architecture the main focus is on large enterprise which have the several challenges and most of the time when speak about enterprise architecture it refer to large system. So the scrum is not suitable for this type enterprise.

- $\quad$ Scrum does not present the specified solution for identified the quo status and desired status, and it focus just on how to improve the quo state. In addition this methodology does not provide efficient way for architecture modelling.

- $\quad$ The goals of product identified without sufficient study about user's requirements. In fact the user story is not adequate for usability perspective.[8] This methodology fails to collect the user's usability needs. [9]

- $\quad$ The term of agile in scrum refer that owner think, it is difficult for development team to have an holistic view in product and desires status.[8]

\subsection{Extreme programming}

Extreme programming is set of various practices that are used in previous methodology. But, it combines these rules and provides new methodology which is more efficient than them in some condition that shows in figure 2, Although it follows some disadvantages which causes to all projects does not use it.

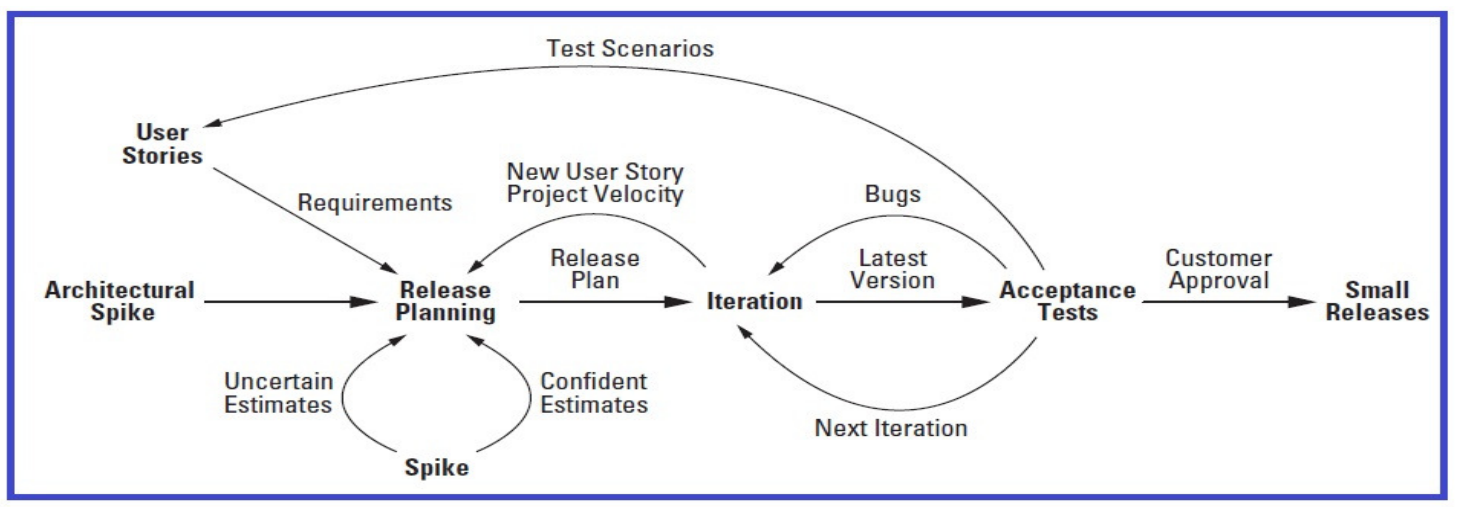

Figure1. Extreme programming project[10] 
$\mathrm{XP}$ can work in project which in initial the requirement is not clear and also it handles small project easily with the best result. But some of the disadvantages of this methodology are:

- $\quad$ For large and even medium enterprise, it cannot use XP methodology because firstly this method need long time and also in big company it will be many complicated based on XP such as large number of customer to handles their requirement and so on.

- $\quad$ Frequently integration is another problem of XP which does not provide reused the code or sharing some similar part of development because of less communication that provided in integration. [7] Also, in traditional organization, integrating agile team cause conflict through management.

- $\quad$ Collaboration between team members in XP especially in large company is difficult and complicated. For instance the high number of team worker cannot discuss in release planning meeting accurately and create conflict. Communication in XP caused challenges.[11] When members work together in project providing coordination through them led some challenges such as "synchronizing availability, adjusting for time differences, and coordinating distribution as well as integration of activities. In addition, document/application sharing among the team members". [12]

- $\quad$ Another important challenge of this methodology is that need strong and expert manager with enough experience to control all system specifically. [13] In some cases need to new strategies that must be decision by manager. CIOs must understand and recognize the challenges to endeavours for covering agile philosophy.

\subsection{Service Oriented Architecture (SOA)}

Service Oriented Architecture(SOA) is an conceptual architecture which want to improve the business by combining to IT concept.[14] On one hand, SOA definition given as" The software architecture of a program or computing system is the structure or structures of the system, which comprise software components, the externally visible properties of those components, and the relationships among them.[15] It has some unique features which distinguish it with other structure. On the other hand Service Oriented Architecture has been defined as "an external, cross-application form of object-oriented programming" because it is provided reusable data and functionality. [16]

Despite many advantages of the Service Oriented Architecture, this method handles many challenges which cause some problem in using it. Many publication focus on three important challenges as main issue of SOA: cost and finance problem, governance and complexity.[17] Based on Alluri's idea the challenges of SOA divided in three parts which each of them handles many item and details. As it mentioned above, it can be alluded that the challenges of SOA have various dimensions which effect on services, but some of them are most effective in agile system that is demonstrated on them below:

- $\quad$ This structure does not present any appropriate modelling for agility.

- $\quad$ According to Ambler et al, “ implementing an SOA environment will cost time and money." [18]

- $\quad$ Often SOA used in classics form while if it merging with agile modelling it will be more agile than before. It means that combining the SOA with incremental method and agile modelling would be effective way for achieving the goals of agility. 
- $\quad$ Complexity is another challenge which happened in SOA due to distributing services. Building an SOA implementation led to system become more complex.[18] So using this method cause to complexity of the project especially in large enterprise that this factor is remarkable. It means that combining and adopting services is from different part needing plan to organize and handle it comprehensively. [19]

\section{SURVEY}

As it clear from data given, the agile methodology is not appropriate for large enterprise and also many of large organisations ignore it. While, applying agility would be noteworthy help for industry due to rapid changes that occurred. Indeed, agile focus on in going project not the future of the project. In fact, many surveys approve this claim. Below demonstrate some related survey as secondary data that shows the less usability of agility in large organization.

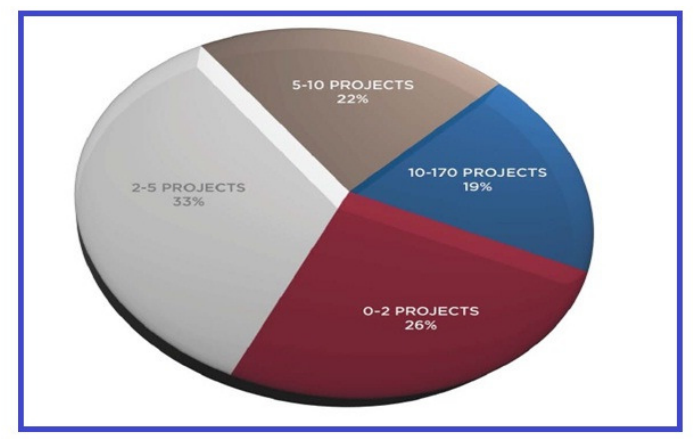

Figure 2.The number of agile projects in company[20]

Based on survey that shows in figure 2 , only 19\% of the studied company use 10-170 agile project. And most of them use agility less than 10 projects. So, many companies do not use agile project or use less agile project. It is obvious that large company which usually has more than 10 project, only few percent of them use agile method. It is clear that this number is less compared to efficiency of the agility. And also figure 3 shows that the main problem of agile method is on managing distributed team. Indeed lack of holistic view is reason of this issue. 
International Journal of Computer Science \& Engineering Survey (IJCSES) Vol.3, No.6, December 2012

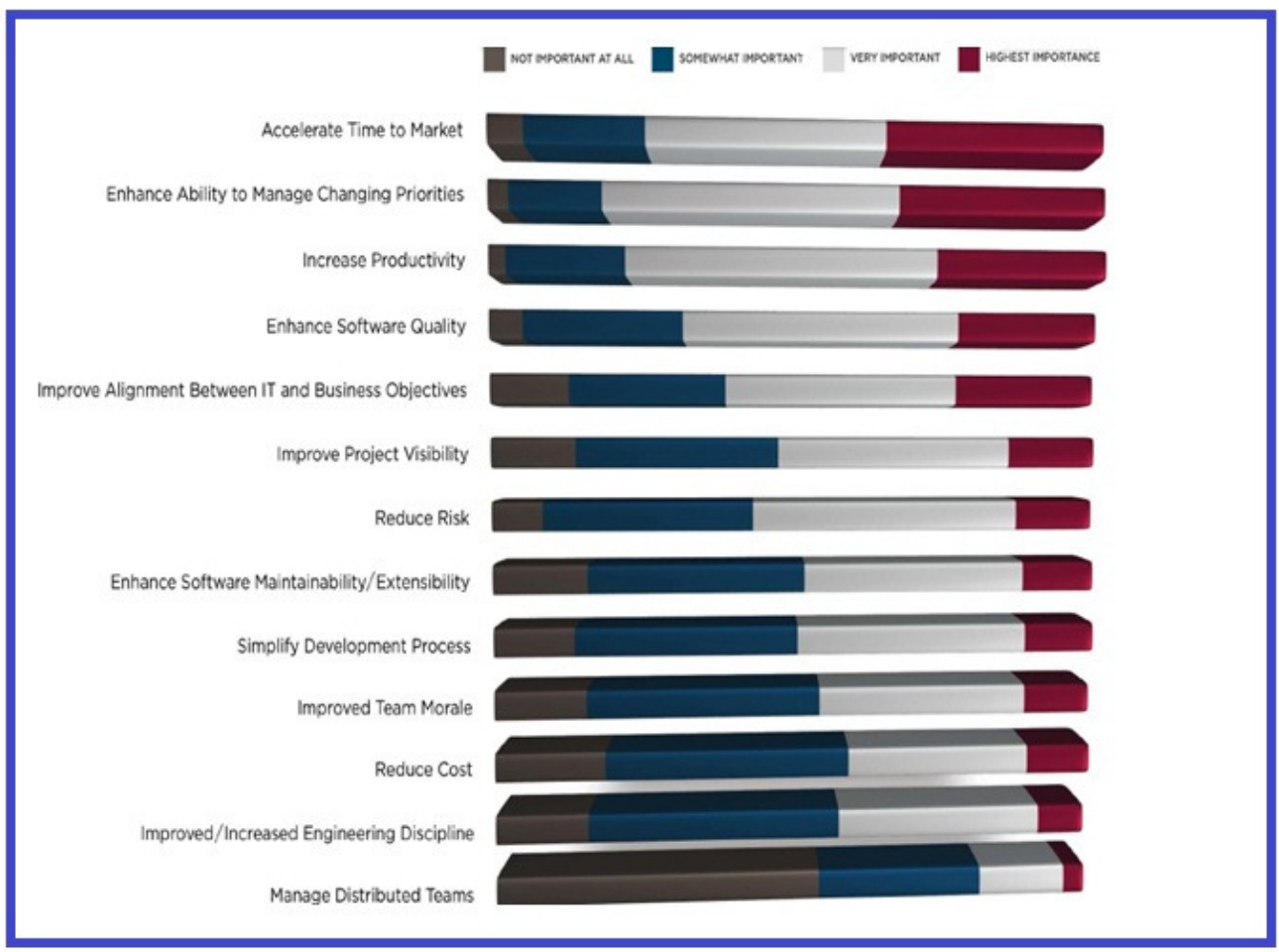

Figure 3.Reason for adopting agile[20]

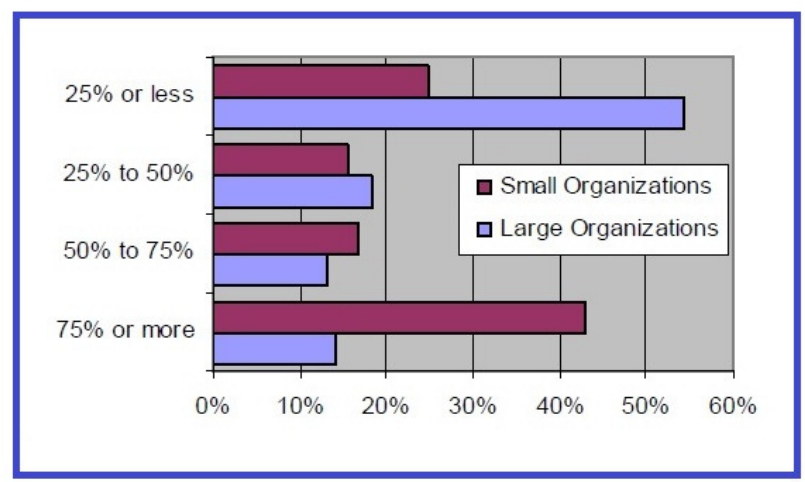

Figure 4.Percentage of development organization staff following agile processes, by organization size[21]

Additionally, Percentage of development organization staff following agile processes, by organization size in figure 4 shows that usually small companies use agile process. Although, it would be efficient for large organisation, but research shows the low rate of agile method in large company. In fact the integration is the main issue of them. And also if they use agile method only very few teams follow it. This is obvious from figure 5 that only less than $5 \%$ of the organisations have more than 100 agile teams. Totally all these surveys show that many organisations especially large one prefer traditional method compared to agile method, while 
using of agile method has positive impact on their industry. The main reason is lack of comprehensive view and schedule to manage and control the large enterprise.

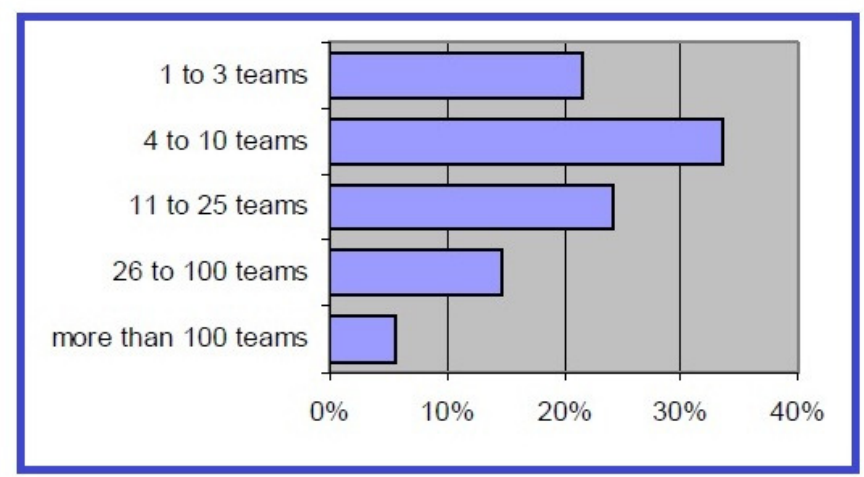

Figure 5.Number of teams following an agile process in larger development organizations[21]

\section{FRAMEWORK AND AGILE ENTERPRISE ARCHITECTURE}

According Brook, developing and implementing solution for software are twisted base on four dimensions: changeability, invisibility, conformity and complexity. [22] As it clear from above challenges of agile method in enterprise architecture, they are not able to support large EA which is more complicated compared to others. Thus, with regard to many advantages of agile method many large organizations ignore it easily. This event happened through to lack of holistic view in project. In fact manager confuses to combine and manage the huge amount of data.

In fact, using framework in enterprise architecture would be significant help to improving the usability of agile method. "An EA framework is an logical structure for classifying and organizing information on the software, hardware, and procedural composition of an EA, including information on how the various architectural components relate to each other in response to the desire to meet a set of system requirements."[23] In fact, EA framework can manage complexity division of view, method and experience. So EA framework is model for developing of EA. Nevertheless, framework provides relevance of taking a holistic view of architectures for enterprise and focus on information system.[24]

Indeed, EA framework can fill the gap of agile method in large enterprise. It can classify the view and method of the system to control and manage it easier.

\section{CONCLUSION}

On the one hand, Enterprise Architecture manages collaboration between humanity, process, business and IT. It is the main notion and common notion of nowadays business. In addition time and changeability of the requirement is another factor which must be considered. On the other hand, Agility is one of efficient factor that is useful in many areas. In enterprise architecture this notion has increased rapidly since technology and IT started to grow. It means that many developers try to understand it and apply them in system due to rapid changes of user requirements. While in large enterprise, they use agile EA less compared to small organisation. 
International Journal of Computer Science \& Engineering Survey (IJCSES) Vol.3, No.6, December 2012

There are several methodologies which follow agile aims such as using XP, Scrum and agility based on Service Oriented Architecture. All these methods handle many advantages which mentioned briefly. Hence depending on enterprise perspective and business environment they are useful. But each of them handles many challenges for applying agility. Further, all of them are not appropriate for large organisation.

In fact, based on survey that indicate in this research most challenges focus on lack of collaboration between IT developer and EA team and difficulty of the integrating the system which is mutual in available methodologies. As it showed in surveys most large company does not use agile method while nowadays agility has many advantages. The main reason is lack of holistic view on system to integrate them accurately. Due to these challenges which are more remarkable in large companies, using framework could be efficient to solve this issue. Using a framework as Meta model for understanding the system and reason of challenges is effective method in enterprise architecture. In enterprise remarkable issue is architecture. It means that providing scheme of the system could be notable help for manager and developer of the companies. It can be concluded that blending of EA framework and agile method can improve the usability of Agile EA in industry particularly large organisation.

\section{REFERENCES}

[1] S. H. Kaisler, F. Armour, and M. Valivullah, "Enterprise architecting: Critical problems," 2005, pp. 224b-224b.

[2] H. Song and Y. T. Song, "Enterprise Architecture Institutionalization and Assessment," pp. 870-875.

[3] P. Abrahamsson, O. Salo, J. Ronkainen, and J. Warsta, Agile software development methods vol. 478: Citeseer, 2002. p 167-168.

[4] M. Cristal, D. Wildt, and R. Prikladnicki, "Usage of Scrum practices within a global company," 2008, pp. 222-226.

[5] H. Guang-yong, "Study and practice of import Scrum agile software development," 2011, p. 217.

[6] K. Schwaber, Agile project management with Scrum. Washington: Microsoft press, 2009. $\mathrm{p} 44$.

[7] M. Mehta and N. Adlakha, "MANIFESTATION OF AGILE METHODS FOR PROMPT SOFTWARE DEVELOPMENT: A REVIEW," IJRIM vol. 2, pp. 249-255, 2012.p 249-255.

[8] M. Singh, "U-SCRUM: An agile methodology for promoting usability," 2008, pp. 555560.

[9] J. Coplien and G. Bjørnvig, Lean architecture: for agile software development: Wiley, 2010. $p$

[10] D. Leffingwell, Scaling software agility: best practices for large enterprises: AddisonWesley Professional, 2007. p

[11] M. Puleio, "How not to do agile testing," in Agile conference, 2006, p. 314.

[12] M. Kircher, P. Jain, A. Corsaro, and D. Levine, "Distributed extreme programming," Extreme Programming and Flexible Processes in Software Engineering, Italy, pp. 66-71, 2001.p 66-71.

[13] S. Nerur, R. K. Mahapatra, and G. Mangalaraj, "Challenges of migrating to agile methodologies," Communications of the ACM, vol. 48, pp. 72-78, 2005.p 72-78. 
International Journal of Computer Science \& Engineering Survey (IJCSES) Vol.3, No.6, December 2012

[14] J. McGovern, S. Tyagi, M. Stevens, and S. Mathew, Java web services architecture: Morgan Kaufmann Pub, 2003. p 44.

[15] L. Bass, P. Clements, and R. Kazman, Software architecture in practice: Addison-Wesley Longman Publishing Co., Inc., 2003. p

[16] D. Woods and T. Mattern, Enterprise SOA: designing IT for business innovation: O'Reilly Media, 2006. $p$

[17] A. Becker, T. Widjaja, and P. Buxmann, "Value Potentials and Challenges of ServiceOriented Architectures," Business \& Information Systems Engineering, pp. 1-12, 2009.p 1-12.

[18] J. McGovern and S. W. Ambler, A practical guide to enterprise architecture: Prentice Hall, 2004. p 88.

[19] N. Bieberstein, Service-oriented architecture compass: business value, planning, and enterprise roadmap: Prentice Hall, 2006. $p$

[20] VersionOneGroup. "State of agile survey." Internet: http://www.trailridgeconsulting.com/surveys/state-of-agile-development-survey-2009.pdf, [2/2/2012].

[21] P. Behrens. "Agile Project Management (APM)Tooling Survey Results." Internet: http://www.trailridgeconsulting.com, [10.2.2012].

[22] F. P. Brooks Jr, "No silver bullet essence and accidents of software engineering," Computer, vol. 20, pp. 10-19, 1987.p 10-19.

[23] A. Goikoetxea, Enterprise Architectures and Digital Administration: Planning, Design and Assessment: World Scientific Publishing Company Incorporated, 2007. p 30.

[24] D. Greefhorst and E. Proper, Architecture Principles: The Cornerstones of Enterprise Architecture vol. 4: Springer. p 8.

\section{Author}

Zahra Askarinejad Amiri is a PhD Candidate of Software Engineering (SE) in University Putra Malaysia (UPM). She received Bachelor of Computer Engineering - Software from University of Science and Culture, Iran. Also she passed master of Software Engineering from Staffordshire University in 2012. Her research interests are Software Engineering, Information System and specifically Enterprise Architecture.

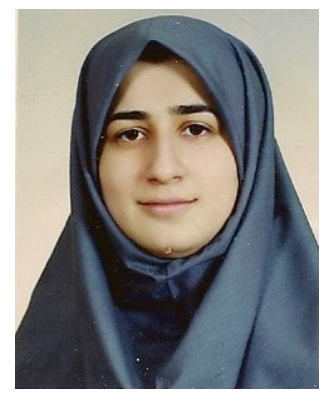

